\title{
Thermoeconomic optimization of a Kalina cycle for a central receiver concentrating solar power plant
}

\author{
Anish Modi*, Martin Ryhl Kærn, Jesper Graa Andreasen, Fredrik Haglind \\ Department of Mechanical Engineering, Technical University of Denmark, Nils Koppels Allé, Building 403, \\ DK-2800 Kgs. Lyngby, Denmark
}

\begin{abstract}
Concentrating solar power plants use a number of reflecting mirrors to focus and convert the incident solar energy to heat, and a power cycle to convert this heat into electricity. This paper evaluates the use of a high temperature Kalina cycle for a central receiver concentrating solar power plant with direct vapour generation and without storage. The use of the ammonia-water mixture as the power cycle working fluid with non-isothermal evaporation and condensation presents the potential to improve the overall performance of the plant. This however comes at a price of requiring larger heat exchangers because of lower thermal pinch and heat transfer degradation for mixtures as compared with using a pure fluid in a conventional steam Rankine cycle, and the necessity to use a complex cycle arrangement. Most of the previous studies on the Kalina cycle focused solely on the thermodynamic aspects of the cycle, thereby comparing cycles which require different investment costs. In this study, the economic aspect and the part-load performance are also considered for a thorough evaluation of the Kalina cycle. A thermoeconomic optimization was performed by minimizing the levelized cost of electricity. The different Kalina cycle simulations resulted in the levelized costs of electricity between 212.2 $\$ \mathrm{MWh}^{-1}$ and $218.9 \$ \mathrm{MWh}^{-1}$. For a plant of same rated capacity, the state-of-the-art steam Rankine cycle has a levelized cost of electricity of $181.0 \$ \mathrm{MWh}^{-1}$. Therefore, when considering both the thermodynamic and the economic perspectives, the results suggest that it is not beneficial to use the Kalina cycle for high temperature concentrating solar power plants.
\end{abstract}

Keywords: Kalina cycle, Ammonia-water mixture, Thermoeconomic optimization, 
Concentrating solar power, Central receiver

\section{Introduction}

Concentrating solar power (CSP) plants are regarded as a viable solution for large scale clean electricity production [1]. One of the biggest challenges faced by the CSP industry today, as compared with the contemporary fossil fuel based alternatives, is the high cost of 5 electricity production. A CSP plant uses a number of reflecting mirrors to focus and convert the incident solar energy to heat, and a power cycle to convert this heat into electricity. In addition, a thermal energy storage system could also be present to store excess heat and use it in times of little or no sunshine. The large investment costs of the CSP plants can be driven down by research in any of these areas through the development of more cost-effective components and improved system designs. One such possibility is the use of ammonia-water mixtures in the CSP plant with a Kalina cycle. The Kalina cycle was introduced in 1984 [2] as an alternative to the conventional steam Rankine cycle to be used as a bottoming cycle for combined cycle power plants. The composition of the ammonia-water mixture used in the cycle is defined by the ammonia mass fraction, i.e. the ratio of the mass of ammonia in the mixture to the total mass of the mixture. The change in the mixture composition affects the thermodynamic and the transport properties of the mixture [3]. Since its introduction, several uses for the Kalina cycle have been proposed in the literature for low temperature applications. Examples include their use in geothermal power plants [4], for waste heat recovery [5-8], for exhaust heat recovery in a gas turbine modular helium reactor [9], in combined heat and power plants [10,11], with a coal-fired steam power plant for exhaust heat recovery [12], as a part of Brayton-Rankine-Kalina triple cycle [13], and in solar plants [14-16]. For high temperature applications, the Kalina cycles have been investigated to be used as gas turbine bottoming cycles [17-20], for industrial waste heat recovery, biomass based cogeneration and gas engine waste heat recovery [21], for direct-fired cogeneration applications [22], and in CSP plants [23-26].

${ }^{*}$ Corresponding author. Tel.: +4545251910

Email address: anmod@mek.dtu.dk (Anish Modi) 
The feasibility of using ammonia-water mixtures at high temperatures has been questioned due to the nitridation effect resulting in the corrosion of the equipment [27]. However, the use of an ammonia-water mixture as the working fluid at high temperature has been successfully demonstrated at the Canoga Park demonstration plant with turbine inlet conditions of $515{ }^{\circ} \mathrm{C}$ and 110 bar [28]. Moreover, a patent by Kalina [29] claims the stability of ammonia-water mixtures along with the prevention of nitridation for plant operation preferably up to $1093{ }^{\circ} \mathrm{C}$ and 689.5 bar using suitable additives. Water itself prevents the ammonia in the mixture from corroding the equipment up to about $400{ }^{\circ} \mathrm{C}$, and above this temperature the amount of the additive is far below the damage threshold [30].

The motivation behind the current study is that the irreversibility during a heat transfer process can be reduced by using a zeotropic mixture, which evaporates and condenses at a varying temperature, contrary to the isothermal evaporation and condensation of a pure fluid [31]. In addition, using a mixture instead of a pure fluid presents an additional degree of freedom in terms of varying the mixture composition in order to obtain better performance from the power cycle. In the previous studies, the Kalina cycle has been evaluated primarily considering the thermodynamic performance of the cycle based on the cycle energy and exergy efficiencies. The reduction in the irreversibility during the heat transfer process with a fluid mixture however comes at a price of increased heat exchanger areas and the need to use a complex cycle layout. These compromises have economic consequences as compared with using a pure fluid. This study focuses on the quantification of these consequences. The primary objective of this paper is to thermoeconomically evaluate the use of a Kalina cycle for a central receiver CSP plant with direct vapour generation and without storage. The presented thermoeconomic optimization methodology includes (1) the thermodynamic design of the Kalina cycle and the solar field, (2) their part-load performances, and (3) the economic model including the cost functions for estimating the capital investment and the operations and maintenance $(\mathrm{O} \& \mathrm{M})$ costs. The results from the thermoeconomic optimization of the Kalina cycle are presented and briefly compared with those for a state-of-the-art steam Rankine cycle. To the authors' knowledge, this is the first attempt at evaluating a high temperature Kalina cycle from both the thermodynamic and economic aspects con- 

power cycle and the solar field models used in the thermoeconomic optimization. Section 3 presents the results from the thermoeconomic optimization and a sensitivity analysis on the various plant costs, Section 4 discusses the results, and Section 5 concludes the paper.

\section{Methods}

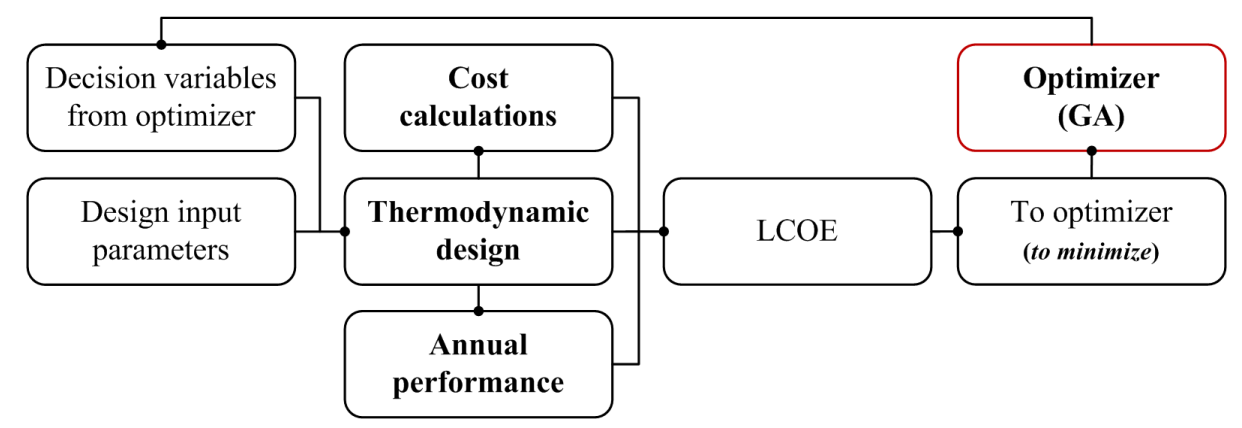

Figure 1: CSP plant thermoeconomic optimization routine.

Fig. 1 shows the steps from the thermoeconomic optimization in this study. The optimization was done using a genetic algorithm (GA). In the methodology, once the design input parameters were fixed, the power cycle and the solar field were designed for the nominal operating condition ('thermodynamic design' in the figure). In case of a CSP plant where the heat source varies throughout the day, and all through the year, it is necessary to include a representative annual performance in order to estimate the plant output over the year. For the annual analysis, the part-load performances of the solar field and the power cycle, the plant site location and meteorological data, and the overall plant control and operation strategies were used to estimate the yearly electricity production. This was done through hourly simulations over a year. The hourly values of the direct normal irradiance (DNI) and other weather data were obtained for a typical meteorological year from Meteonorm [32]. The heat input to the power cycle was obtained using the DNI values together with the part-load performance of the solar field. The net electricity output was then calculated using the part-load performance of the power cycle for the available heat input. 
Once the thermodynamic performance (design, part-load, and annual) was computed for a given set of input parameters, the next step was to include suitable cost functions in order to estimate the capital investment and the O\&M costs for the power plant. An economic model with the plant lifetime and the insurance and interest rates as inputs was used to estimate the value of the thermoeconomic objective. For CSP plants, the levelized cost of electricity (LCOE) is the frequently preferred indicator for comparing alternatives [33,34], and therefore also used here. The LCOE represents the average cost of electricity production over the lifetime of the power plant, considering the costs for both building and operating the plant. For a solar-only plant, the LCOE can be defined as follows [35]:

$$
\mathrm{LCOE}=\frac{\mathrm{CRF} \cdot C_{\mathrm{inv}}+C_{\mathrm{O \& M}, \mathrm{y}}}{E_{\mathrm{y}}}
$$

with

$$
\mathrm{CRF}=k_{i}+\frac{k_{d} \cdot\left(1+k_{d}\right)^{N_{p}}}{\left(1+k_{d}\right)^{N_{p}}-1}
$$

where $\mathrm{CRF}$ is the capital recovery factor, $C_{\mathrm{inv}}$ and $C_{\mathrm{O} \& \mathrm{M}, \mathrm{y}}$ are the plant total capital investment costs and the yearly O\&M cost, $E_{\mathrm{y}}$ is the yearly electricity production, $k_{i}$ and $k_{d}$ are the annual insurance and real debt interest rates, and $N_{p}$ is the plant lifetime in years. The Kalina cycle design and part-load models, the solar field model, and the cost functions are presented in the subsections below.

All the Kalina cycle simulations were performed using MATLAB R2015a [36] with the solar field designed using DELSOL3 [37]. The thermodynamic properties for the ammonia-water mixtures were calculated using the REFPROP 9.1 interface for MATLAB [38]. The default property calculation method for the ammonia-water mixtures in REFPROP is using the Tillner-Roth and Friend formulation [39]. However, this formulation in REFPROP is highly unstable and fails to converge on several occasions, especially in the two-phase regions, near the critical point, and at higher ammonia mass fractions. Therefore, an alternative formulation called 'Ammonia (Lemmon)' [40] was used. It was found to be more stable and with fewer convergence failures, without significantly compromising on the accuracy of the calculations [41]. The specific enthalpy and the specific entropy values for about 2400 combinations of pressures, temperatures, and ammonia mass fractions be- 
tween 1 bar and 160 bar, $52^{\circ} \mathrm{C}$ and $527^{\circ} \mathrm{C}$, and 0.3 and 0.9 , respectively, were compared for the two methods. The maximum and the average deviations of the Ammonia (Lemmon) formulation from the Tillner-Roth and Friend formulation for the specific enthalpy values were found to be $6.97 \%$ and $1 \%$, while for the specific entropy values were found to be $4.49 \%$ and $0.65 \%$ [25]. As the steam Rankine cycle based CSP plants have been in commercial operation for several years, the Kalina cycle CSP plant performance was compared with that of a state-of-the-art steam Rankine cycle CSP plant. An established CSP software, System Advisor Model 2015.6.30 [42], was used to analyse the steam Rankine cycle CSP plants. For a fair comparison, the same design assumptions were made for the steam Rankine cycle simulations as were made for the Kalina cycle CSP plants. All the costs mentioned here are in United States Dollars $(\$)$.

\subsection{Kalina cycle}

The Kalina cycle layout investigated in this paper, named KC12 [25], is shown in Fig. 2. The cycle components in the layout are shown in abbreviated forms where REC is the receiver/boiler, TUR is the turbine, GEN is the generator, SEP is the vapour-liquid separator, $\mathrm{RE} *$ is the recuperator, $\mathrm{PU} *$ is the pump, $\mathrm{CD} *$ is the condenser, $\mathrm{MX} *$ is the mixer (where ' $*$ ' denotes the respective component number), SPL is the splitter, and THV is the throttling valve.

In the cycle, the superheated ammonia-water mixture (stream 1), i.e. the working solution, expands in the turbine and is subsequently mixed in the mixer MX1 with the ammonia lean liquid from the separator SEP to lower the ammonia mass fraction in the condenser CD1. The fluid after the mixer MX1 is called the basic solution. The ammonia rich vapour from the separator SEP is mixed in the mixer MX2 with a part of the basic solution from the splitter SPL in order to obtain the working solution ammonia mass fraction. This working solution then passes through the condenser CD2 and the pump PU2. The external heat input to the working fluid is provided in the solar receiver REC.

A methodology to obtain the nominal operating condition for the Kalina cycle KC12 was presented in detail by Modi et al. [26]. The validation of the general solution algorithm for 


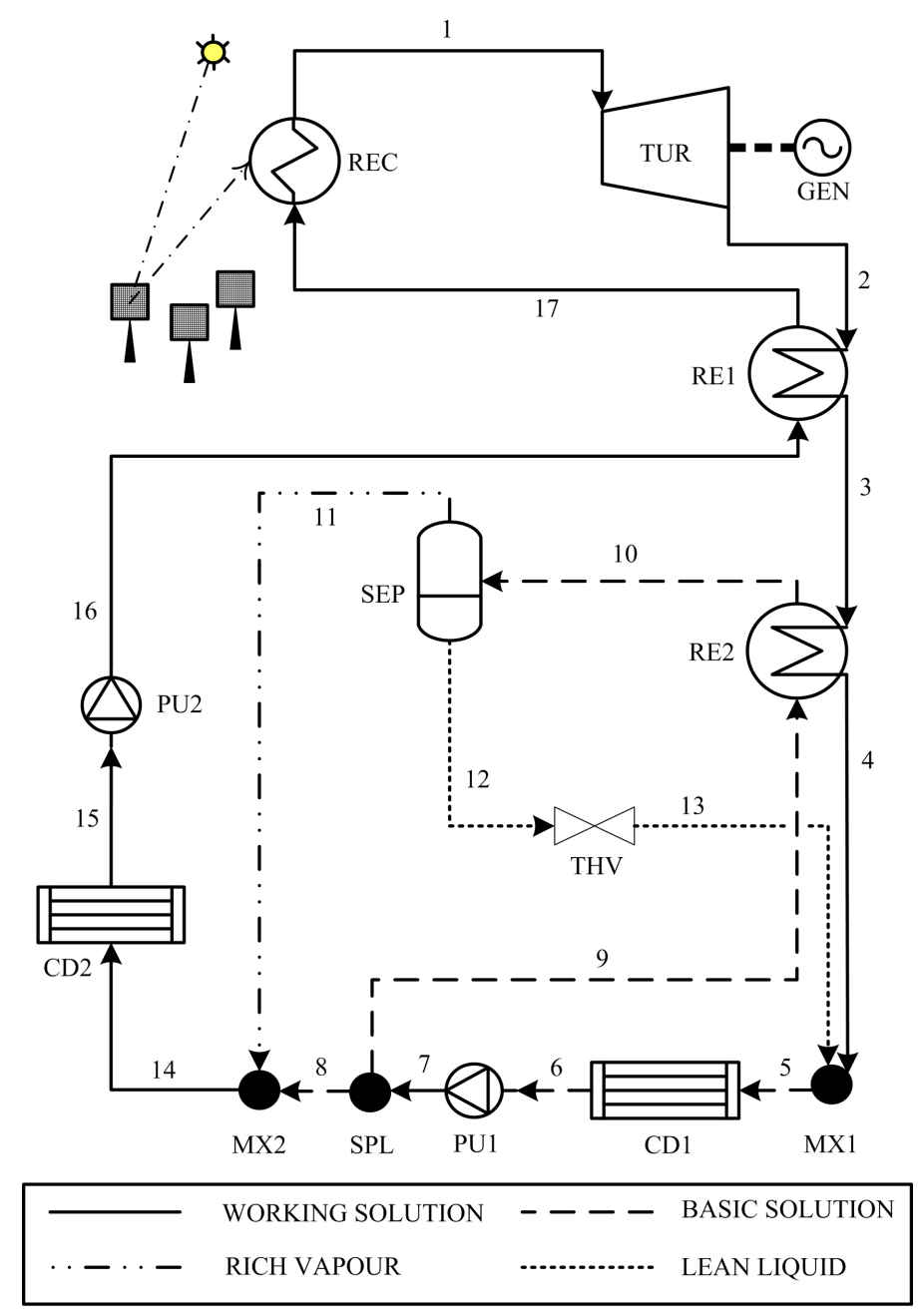

Figure 2: Kalina cycle KC12.

the high temperature Kalina cycles was also presented [26]. The following assumptions were made for the thermodynamic design of the Kalina cycle CSP plant [25,35]. The plant was designed for a net electrical power output $\left(\dot{W}_{\text {net }}\right)$ of $20 \mathrm{MW}$. The turbine inlet temperature $\left(T_{1}\right)$ was fixed at $500{ }^{\circ} \mathrm{C}$. The design point isentropic efficiency was $85 \%$ for the turbine $\left(\eta_{\text {tur,is }}\right)$ and $70 \%$ for the pumps $\left(\eta_{\mathrm{pu}, \mathrm{is}}\right)$. The turbine mechanical efficiency $\left(\eta_{\mathrm{tur}, \mathrm{m}}\right)$ and the generator efficiency $\left(\eta_{\text {gen }}\right)$ were both $98 \%$. The minimum allowed vapour quality at the turbine outlet $\left(X_{2, \min }\right)$ was $90 \%$. The condenser cooling water inlet $\left(T_{\mathrm{cw}, \text { in }}\right)$ and outlet $\left(T_{\mathrm{cw}, \text { out }}\right)$ temperatures were fixed at $20{ }^{\circ} \mathrm{C}$ and $30{ }^{\circ} \mathrm{C}$, respectively. The recuperators $\left(\Delta T_{\mathrm{pp}, \mathrm{re}, \min }\right)$ and the condensers $\left(\Delta T_{\mathrm{pp}, \mathrm{cd} \text {,min }}\right)$ had a minimum pinch point temperature difference of $8{ }^{\circ} \mathrm{C}$ 


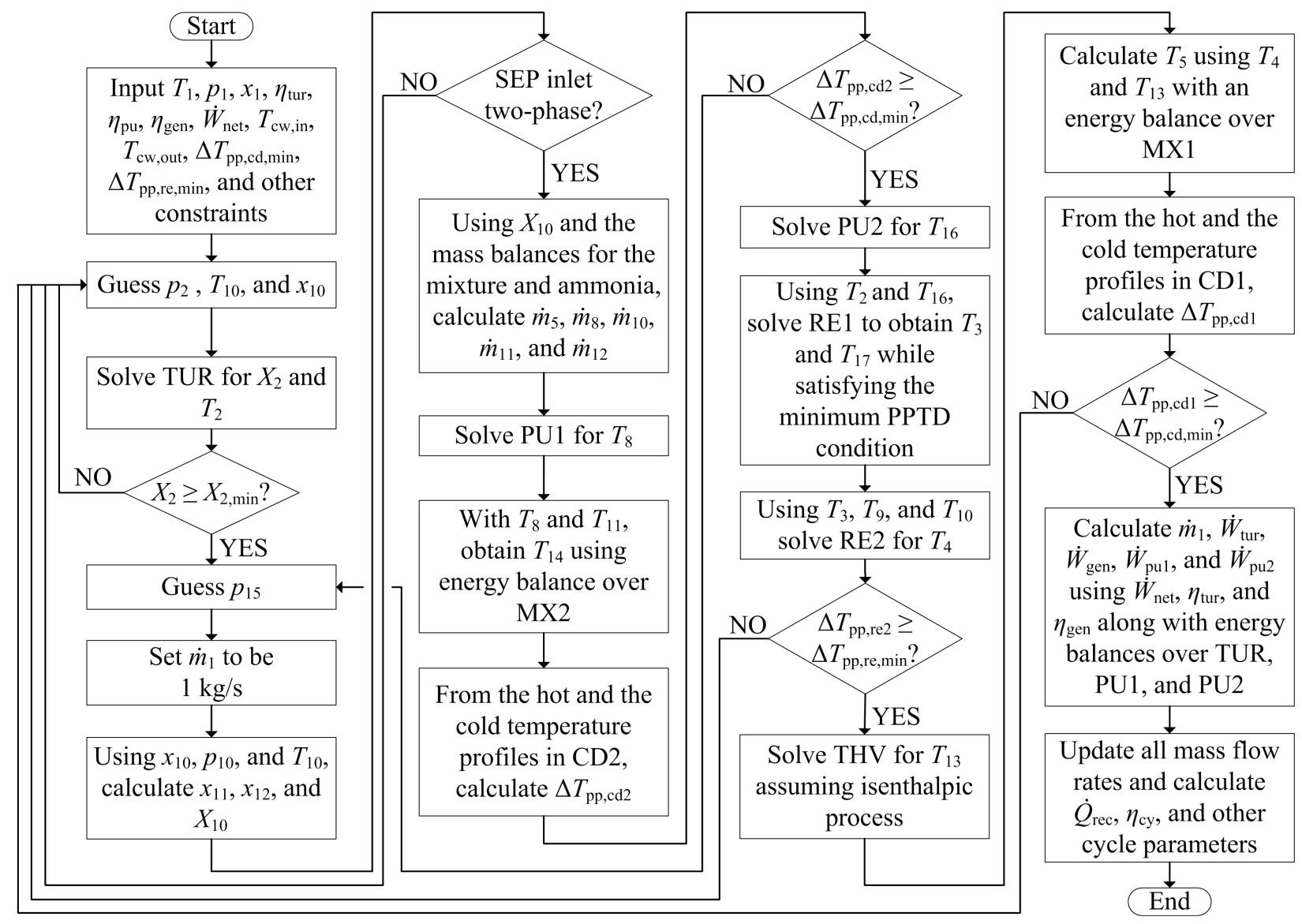

Figure 3: Solution algorithm for the thermodynamic design of the Kalina cycle KC12.

and $4{ }^{\circ} \mathrm{C}$, respectively. The minimum separator inlet vapour quality $\left(X_{10, \text { min }}\right)$ was fixed at $5 \%$, and the pressure drops and heat losses were neglected. For the economic model, the plant lifetime $\left(N_{p}\right)$ was assumed to be 30 years and the annual insurance rate $\left(k_{i}\right)$ and the real debt interest rate $\left(k_{d}\right)$ were assumed to be $1 \%$ and $8 \%$, respectively [35].

For brevity, the methodology to obtain the nominal operating condition for the Kalina cycle KC12 is presented as a flow chart in Fig. 3. In general, the following steps were used to solve the Kalina cycle for each iteration of the optimization process [26]. The turbine TUR was solved first to obtain the state at the turbine outlet. Assuming a condenser pressure for the condenser CD2, the mass flow rates were then obtained using a simplified configuration as presented in Marston [17] and elaborated in Modi et al. [26] for the KC12 layout. Once the mass flow rates at different points in the cycle were known, and it was made sure that 
the inlet stream to the separator SEP is in two-phase flow, then the pumps, the mixers, the the heat transfer [46]. The tube pitch to tube outer diameter ratio was maintained between 1.25 and 1.5, and a baffle cut of $25 \%$ was fixed for the heat exchanger area calculations, two 
common design assumptions for shell-and-tube heat exchangers [46]. Using the geometrical constraints and the design mass flow rates, the required number of tubes was minimized until the maximum allowable flow velocity was reached on either the shell or the tube side. As the temperature profiles in the heat exchangers were not always linear, the heat exchangers were discretized into 50 control volumes on the basis of the heat transfer rate for pinch calculation. The total area of the heat exchanger would then be the sum of the areas of all the control volumes. Table 1 provides an overview of the heat transfer correlations used in this study.

Table 1: Heat transfer correlations used in the estimation of the heat exchanger area.

\begin{tabular}{ll}
\hline Description & Correlation \\
\hline Single phase in-tube flow & Gnielinski (1976) [47] \\
Condensing in-tube flow & Shah $(2013)$ with Silver-Bell-Ghaly (1972) correc- \\
& tion for mixtures $[48,49]$ \\
Evaporating in-tube flow & Shah (1982) [50] \\
Single phase shell-side flow & Kern (1950) as presented in Smith $(2005)[45,51]$ \\
Condensing shell-side flow & Kern (1950) as presented in Smith (2005), \\
& with Silver-Bell-Ghaly (1972) correction for mix- \\
\hline & tures $[45,49,51]$ \\
\hline
\end{tabular}

Once the thermodynamic states, the different mass flow rates, and the heat exchanger areas were estimated from the cycle design, the part-load calculations were performed as elaborated in Modi et al. [26]. For the part-load operation, the following control strategy was used. A sliding pressure operation was assumed while maintaining the turbine inlet temperature at the design value. In order to obtain the highest part-load performance from the cycle, the separator inlet ammonia mass fraction was varied. In practice, it is easier to measure the temperatures and pressures in the cycle than to measure the ammonia mass fraction, especially when the mixture is in two-phase flow. Since the pressure at the pump 
PU1 outlet is governed by the condenser CD2, the splitter SPL split fraction (i.e. the ratio of the mass flow rate of stream 9 to that of stream 7 in Fig. 2) needs to be varied to obtain the required optimal separator inlet ammonia mass fraction. This split fraction can be varied by changing the splitter SPL valve position, and this position in turn determines the separator inlet ammonia mass fraction. For a given value of the pump PU1 outlet pressure (which is also the separator SEP inlet pressure), there will be only one combination of the temperature and the ammonia mass fraction at the separator SEP inlet which results in the highest part-load performance. Thus, the separator SEP inlet temperature can be monitored in order to specify the optimal splitter valve position (and thus the optimal split fraction) for the different part-load operating conditions. The different plant equipment were modelled in part load as follows. The turbine was modelled in part load using the Stodola's ellipse law which relates the temperature, pressure, and mass flow rate at the turbine inlet, and the pressure at the turbine outlet [52] through a turbine constant $\left(k_{t u r}\right)$ as shown below:

$$
k_{t u r}=\frac{\dot{m}_{1} \cdot \sqrt{T_{1}}}{\sqrt{p_{1}^{2}-p_{2}^{2}}}
$$

while the off-design isentropic efficiency of the turbine was estimated from [53]:

$$
\eta_{\mathrm{tur}, \mathrm{is}}=\eta_{\mathrm{tur}, \mathrm{is}, \mathrm{d}}-2 \cdot\left[\frac{N_{\mathrm{tur}}}{N_{\mathrm{tur}, \mathrm{d}}} \cdot \sqrt{\frac{\Delta h_{\mathrm{is}, \mathrm{tur}, \mathrm{d}}}{\Delta h_{\mathrm{is}, \mathrm{tur}}}}-1\right]^{2}
$$

where $\eta_{\text {tur,is }}$ and $\eta_{\text {tur,is,d }}$ are the turbine isentropic efficiencies at part-load and design conditions, $N_{\text {tur }}$ and $N_{\text {tur,d }}$ are the turbine rotational speeds at part-load and design conditions, and $\Delta h_{\mathrm{is}, \text { tur }}$ and $\Delta h_{\mathrm{is}, \mathrm{tur}, \mathrm{d}}$ are the isentropic specific enthalpy differences across the turbine at part-load and design conditions. The turbine speed in a power plant is always maintained at the design value in order to maintain the frequency of the generated electricity at a constant value, and therefore the ratio of the speeds in Eq. 4 is taken as unity [53]. Although the mechanical losses typically remain constant in absolute terms during part-load operation, the mechanical efficiency of the turbine was assumed to stay the same as its design value for simplification. 
The off-design isentropic efficiency of the pumps was obtained from [54]:

$$
\eta_{\mathrm{pu}, \mathrm{is}}=\eta_{\mathrm{pu}, \mathrm{is}, \mathrm{d}} \cdot\left[2 \cdot \frac{\dot{m}_{\mathrm{pu}}}{\dot{m}_{\mathrm{pu}, \mathrm{d}}}-\left(\frac{\dot{m}_{\mathrm{pu}}}{\dot{m}_{\mathrm{pu}, \mathrm{d}}}\right)^{2}\right]
$$

where $\eta_{\mathrm{pu}, \text { is }}$ and $\eta_{\mathrm{pu}, \mathrm{is}, \mathrm{d}}$ are pump efficiencies at part-load and design conditions, and $\dot{m}_{\mathrm{pu}}$ and $\dot{m}_{\mathrm{pu}, \mathrm{d}}$ are the mass flow rate through the pump at part-load and design conditions.

The off-design generator efficiency was obtained from [55]:

$$
\eta_{\text {gen }}=\frac{\eta_{\text {gen }, \mathrm{d}} \cdot \zeta_{\text {gen }}}{\eta_{\text {gen }, \mathrm{d}} \cdot \zeta_{\text {gen }}+\left(1-\eta_{\text {gen,d }}\right) \cdot\left[\left(1-F_{c u}\right)+F_{c u} \cdot \zeta_{\text {gen }}^{2}\right]}
$$

where $F_{c u}$ is the copper loss fraction (assumed $0.43[55]$ ), $\eta_{\text {gen }}$ and $\eta_{\text {gen,d }}$ are the generator efficiencies at part-load and design conditions, and $\zeta_{\text {gen }}$ is the generator load relative to the design value.

The heat exchangers were again discretized in the part-load conditions to obtain the temperature profiles so as to ensure that there were no pinch violations. The UA values in part load were obtained using the power law as shown below [26]:

$$
(\mathrm{UA})_{\mathrm{i}}=(\mathrm{UA})_{\mathrm{i}, \mathrm{d}} \cdot\left(\frac{\dot{m}}{\dot{m}_{\mathrm{d}}}\right)^{0.8}
$$

where $(\mathrm{UA})_{\mathrm{i}}$ and $(\mathrm{UA})_{\mathrm{i}, \mathrm{d}}$ are the UA values at part-load and design conditions for the $i^{\text {th }}$ control volume, $U$ is the overall heat transfer coefficient, $A$ is the heat transfer area based on the tube outside diameter, and $\dot{m}$ and $\dot{m}_{\mathrm{d}}$ are the mass flow rates of the cold fluid at part-load and design conditions.

\subsection{Solar field}

A central receiver solar field includes a number of heliostats with two-axis tracking to follow the sun and concentrate the sunlight on a receiver placed on the top of a tower. For the current study, an external cylindrical receiver with direct vapour generation and a surrounding heliostat field were assumed [56]. The central receiver solar field was designed with Seville, Spain as the plant location $\left(37.25^{\circ} \mathrm{N}, 5.54^{\circ} \mathrm{W}\right)$. This location was considered as there are already several CSP plants that have been built in the region, and are currently in operation [57]. A design DNI value of $900 \mathrm{~W} \mathrm{~m}^{-2}$ and a solar multiple of 1.3 were 
assumed [34]. Fig. 4 highlights the various losses between the energy in the incident DNI and the final heat absorbed by the heat transfer fluid in the receiver. For the direct vapour generation configuration in this study, the receiver heat transfer fluid is the same as the power cycle working fluid.

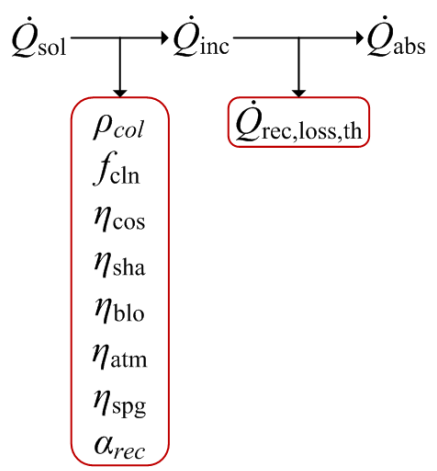

Figure 4: Energy loss mechanisms in the central receiver solar field with direct vapour generation.

In Fig. $4, \dot{Q}_{\text {sol }}$ is the energy in the incident DNI at the plant site and $\dot{Q}_{\text {inc }}$ is the energy incident on the receiver surface after the losses due to heliostat reflection, cosine effect, shadowing and blocking, atmospheric attenuation, spillage, and receiver reflection [56]. $\dot{Q}_{\text {rec,loss,th }}$ accounts for the receiver convective and radiative thermal losses [41]. Once the required heat input to the power cycle (obtained from the power cycle design) and the solar multiple value were provided as an input to DELSOL3, the software calculated the required receiver dimensions (the height and the diameter), the tower height, the heliostat field layout, and the required land area by minimizing the energy cost for the given assumptions and bounds.

At part-load conditions, the solar field was operated as follows. In case there is more heat available than the design heat input to the receiver, some heliostats will be defocused to prevent the receiver from operating outside the design conditions. In case the available energy input to the power cycle from the receiver is lower than the minimum power cycle operating point (assumed $20 \%$ of the design rated capacity), the power plant will be shut down. The heat absorbed by the ammonia-water mixture in the receiver during part-load operation is given by:

$$
\dot{Q}_{\mathrm{abs}}=\mathrm{DNI} \cdot A_{\mathrm{col}} \cdot \eta_{\mathrm{SF}}-\dot{Q}_{\mathrm{rec}, \mathrm{loss}, \mathrm{th}}
$$


where the solar field efficiency $\left(\eta_{\mathrm{SF}}\right)$ is given by:

$$
\eta_{\mathrm{SF}}=\left(\rho_{\text {col }} \cdot f_{\mathrm{cln}}\right) \cdot \eta_{\mathrm{cos}} \cdot \eta_{\mathrm{sha}} \cdot \eta_{\mathrm{blo}} \cdot \eta_{\mathrm{atm}} \cdot \eta_{\mathrm{spg}} \cdot \alpha_{\text {rec }}
$$

and $A_{\text {col }}$ is the total heliostat field (collector) aperture area obtained from the solar field design using DELSOL3, $\rho_{\text {col }}$ is the heliostat mirror reflectivity, $f_{\text {cln }}$ is the average mirror cleanliness, $\alpha_{r e c}$ is the average receiver absorptivity, and $\eta_{\cos }$ is the field cosine efficiency. The terms $\eta_{\text {sha }}, \eta_{\text {blo }}, \eta_{\text {atm }}$, and $\eta_{\text {spg }}$ respectively represent the shadowing efficiency $(1-$ shadowing loss), the blocking efficiency (1 - blocking loss), the atmospheric transmittance (1 - atmospheric attenuation), and the receiver intercept factor (1 - spillage) as defined in Kistler [56] and Modi [41]. As the power cycle operates in part load with the design turbine inlet temperature, the average receiver surface temperature $\left(\bar{T}_{\text {rec }}\right)$ was conservatively assumed to remain the same at part-load conditions [58]. Assuming the ambient temperature remains near the design value for simplification, the receiver thermal loss $\left(\dot{Q}_{\text {rec,loss,th }}\right)$ was thus fixed at its design value during part-load operation [58].

The solar field efficiency $\left(\eta_{\mathrm{SF}}\right)$ during part-load operation was calculated in two steps based on the sun's position in the sky. The first step was to create a matrix of the solar field efficiency (including all the efficiencies and factors) from DELSOL3 using the heliostat layout from the design run. This matrix provides the solar field efficiency as a function of the solar azimuth and the zenith angles. The second step was to calculate the solar azimuth and the zenith angles for every hour of the year using the equations specified in Duffie and Beckman [59], and interpolate the solar field efficiency for any hour from the matrix obtained from DELSOL3. In this study, the solar angles were calculated at the beginning of every hour for their use in the annual performance calculations.

\subsection{Cost functions}

The cost functions used to estimate the capital investment and the O\&M costs are presented in this section. In order to consider the effect of inflation since the cost functions were first published, all the capital investment costs were scaled by the Marshall and Swift equipment cost indices to represent the costs in January 2014 values [60], except for the 
ones taken from NREL [42] as they were already from a 2015 version of the software, and therefore maintained at the current values as a conservative assumption. The cost scaling was done by multiplying the cost obtained from the cost function by the equipment cost index multiplication factor, i.e. the ratio of the Marshall and Swift equipment cost index from January 2014, to that of the year when the cost function was first published. An example is shown below:

$$
C=C_{\mathrm{CF}} \cdot\left(\frac{f_{\mathrm{M \& S}}^{2014}}{f_{\mathrm{M} \& \mathrm{~S}}^{\mathrm{CF}, \mathrm{y}}}\right)
$$

where $C$ is the January 2014 cost, $C_{\mathrm{CF}}$ is the cost estimated using the cost function, and $f_{\mathrm{M} \& \mathrm{~S}}^{2014}$ and $f_{\mathrm{M} \& \mathrm{~S}}^{\mathrm{CF}}$ are the Marshall and Swift cost indices respectively for January 2014 and the year in which the cost function was first published. For brevity, all the capital cost functions are mentioned here without the equipment cost index multiplication factor.

The total capital investment cost $\left(C_{\text {inv }}\right)$ for the Kalina cycle CSP plant was estimated as the sum of the power cycle cost $\left(C_{\mathrm{PC}}\right)$, the solar field cost $\left(C_{\mathrm{SF}}\right)$, the land purchasing cost $\left(C_{\text {land }}\right)$, and the contingencies over these three costs $\left(C_{\mathrm{cnt}}\right)$ as shown below:

$$
C_{\mathrm{inv}}=C_{\mathrm{PC}}+C_{\mathrm{SF}}+C_{\text {land }}+C_{\mathrm{cnt}}
$$

The power cycle cost was calculated using Eq. (12) as the sum of the equipment $\operatorname{cost}\left(C_{\mathrm{PC}, \text { eqp }}\right)$ and the miscellaneous cost $\left(C_{\mathrm{PC}, \mathrm{misc}}\right)$. The equipment cost $\left(C_{\mathrm{PC} \text {,eqp }}\right)$ consisted of the capital investment cost for the turbine $\left(C_{\text {tur }}\right)$, the generator $\left(C_{\text {gen }}\right)$, the pumps $\left(C_{\mathrm{pu}}\right)$, the heat exchangers - recuperators $\left(C_{\mathrm{re}}\right)$ and condensers $\left(C_{\mathrm{cd}}\right)$, and the vapour-liquid separator $\left(C_{\mathrm{sep}}\right)$, as shown in Eq. 13. The miscellaneous cost $\left(C_{\mathrm{PC}, \text { misc }}\right)$ included the piping cost $\left(C_{\mathrm{PC}, \mathrm{pip}}\right)$, the instrumentation and control system cost $\left(C_{\mathrm{PC}, \text { insc }}\right)$, the electrical equipment and materials $\operatorname{cost}\left(C_{\mathrm{PC}, \mathrm{el}}\right)$, and the installation cost $\left(C_{\mathrm{PC}, \text { inst }}\right)$, as shown in Eq. 14.

$$
\begin{aligned}
C_{\mathrm{PC}} & =C_{\mathrm{PC}, \text { eqp }}+C_{\mathrm{PC}, \text { misc }} \\
C_{\mathrm{PC}, \text { eqp }} & =C_{\mathrm{tur}}+C_{\mathrm{gen}}+\sum C_{\mathrm{pu}}+\sum C_{\mathrm{re}}+\sum C_{\mathrm{cd}}+C_{\mathrm{sep}} \\
C_{\mathrm{PC}, \text { misc }} & =C_{\mathrm{PC}, \text { pip }}+C_{\mathrm{PC}, \text { insc }}+C_{\mathrm{PC}, \mathrm{el}}+C_{\mathrm{PC}, \text { inst }}
\end{aligned}
$$

The Kalina cycle turbine and pump costs, with the turbine power output $\left(\dot{W}_{\text {tur }}\right)$ and the 
required pump power $\left(\dot{W}_{\mathrm{pu}}\right)$ in $\mathrm{kW}$, were estimated using the correlations from Dorj [61]:

$$
\begin{aligned}
& C_{\mathrm{tur}}=4405 \cdot \dot{W}_{\mathrm{tur}}^{0.7} \\
& C_{\mathrm{pu}}=1120 \cdot \dot{W}_{\mathrm{pu}}^{0.7}
\end{aligned}
$$

where the turbine power output $\left(\dot{W}_{\text {tur }}\right)$ and the required pump power $\left(\dot{W}_{\text {pu }}\right)$ were obtained as explained in Modi et al. [26].

The cost of the generator and electrical auxiliaries were estimated using the generator electrical power output $\left(\dot{W}_{\text {gen }}\right)$ in $\mathrm{kW}$ with the correlation by Pelster [62]:

$$
C_{\text {gen }}=10 \times 10^{6} \cdot\left(\frac{\dot{W}_{\text {gen }}}{160 \times 10^{3}}\right)^{0.7}
$$

The cost of the various heat exchangers in the cycle (the recuperators and the condensers) were estimated using the heat exchanger area $\left(A_{\mathrm{hx}}\right)$ with the correlation by Smith [45]:

$$
C_{\mathrm{hx}}=32800 \cdot\left(\frac{A_{\mathrm{hx}}}{80}\right)^{0.8} \cdot f_{\mathrm{pres}} \cdot f_{\mathrm{temp}}
$$

where the pressure $\left(f_{\text {pres }}\right)$ and the temperature $\left(f_{\text {temp }}\right)$ correction factors were calculated as suggested in Smith [45].

The separator cost $\left(C_{\text {sep }}\right)$ was estimated assuming it to be a vertical vessel using the following equation $[63,64]$ :

$$
C_{\text {sep }}=f_{\text {pres }} \cdot 10^{f_{\mathrm{s} 1}+f_{\mathrm{s} 2} \cdot \log _{10} H_{\mathrm{sep}}+f_{\mathrm{s} 3} \cdot\left(\log _{10} H_{\mathrm{sep}}\right)^{2}}
$$

where the height of the separator $\left(H_{\text {sep }}\right)$ was calculated using the volumetric flow rate at the separator inlet assuming a residence time of 3 min and a height to diameter ratio equal to 3 , common specification assumptions in commercial models [65]. The pressure correction factor $\left(f_{\text {pres }}\right)$ and the other cost factors $\left(f_{\mathrm{s} 1}, f_{\mathrm{s} 2}\right.$, and $\left.f_{\mathrm{s} 3}\right)$ were calculated as suggested in Ulrich [63]. The piping cost $\left(C_{\mathrm{PC} \text {,pip }}\right)$, the instrumentation and control system cost $\left(C_{\mathrm{PC} \text {,insc }}\right)$, the electrical equipment and material cost $\left(C_{\mathrm{PC}, \mathrm{el}}\right)$, and the installation cost $\left(C_{\mathrm{PC} \text {,inst }}\right)$ were respectively assumed to be $66 \%, 10 \%, 10 \%$, and $45 \%$ of the power cycle equipment costs $\left(C_{\text {PC,eqp }}\right)$ as suggested in Bejan et al. [66]. 
The total solar field cost $\left(C_{\mathrm{SF}}\right)$ included the cost of the heliostat mirror collectors $\left(C_{\mathrm{col}}\right)$, the tower $\left(C_{\text {tow }}\right)$, the receiver $\left(C_{\text {rec }}\right)$, and site improvement $\left(C_{\text {site }}\right)$ given by [42]:

$$
\begin{aligned}
& C_{\mathrm{SF}}=C_{\mathrm{col}}+C_{\mathrm{tow}}+C_{\mathrm{rec}}+C_{\mathrm{site}} \\
& C_{\mathrm{col}}=170 \cdot A_{\mathrm{col}} \\
& C_{\mathrm{tow}}=3 \times 10^{6} \cdot \exp \left[0.0113 \cdot\left(\frac{H_{\mathrm{tow}}-H_{\mathrm{rec}}}{2}+\frac{H_{\mathrm{col}}}{2}\right)\right] \\
& C_{\mathrm{rec}}=55402800 \cdot\left(\frac{\pi \cdot D_{\mathrm{rec}} \cdot H_{\mathrm{rec}}}{1110}\right)^{0.7} \\
& C_{\mathrm{site}}=15 \cdot A_{\mathrm{col}}
\end{aligned}
$$

$$
C_{\mathrm{cnt}}=0.2 \cdot\left(C_{\mathrm{PC}}+C_{\mathrm{SF}}+C_{\text {land }}\right)
$$

A sensitivity analysis on the results of the thermoeconomic optimization was performed in order to identify the parameters that affect the cost of the CSP plant the most. For the sensitivity analysis, the different cost parameters for the Kalina cycle CSP plant were varied by $\pm 30 \%$ from their optimal values and their effect on the LCOE was assessed. The varied parameters were the the solar field capital investment cost $\left(C_{\mathrm{SF}}\right)$, the power cycle capital investment cost $\left(C_{\mathrm{PC}}\right)$, the land purchase cost $\left(C_{\text {land }}\right)$, the contingency cost $\left(C_{\text {cnt }}\right)$, and the fixed and variable O\&M costs $\left(C_{\mathrm{O} \& \mathrm{M}, \text { fix }}\right.$ and $\left.C_{\mathrm{O} \& \mathrm{M}, \mathrm{var}}\right)$. In addition, the capital investment 
cost for the various solar field and power cycle components were also varied for a better insight into the results.

\section{Results}

Fig. 5 shows the variation of the LCOE for different turbine inlet pressures and ammonia mass fractions at a turbine inlet temperature of $500{ }^{\circ} \mathrm{C}$. The results suggest that the LCOE is relatively more sensitive to the turbine inlet pressure than the turbine inlet ammonia mass fraction. All the combinations of the turbine inlet pressures and ammonia mass fractions result in a close range of LCOE values, between $212.2 \$ \mathrm{MWh}^{-1}$ and $218.9 \$ \mathrm{MWh}^{-1}$. This is because of the large share of the solar field in the capital investment cost (about $53 \%$ ) which governs the overall cost structure of the plant. The total plant specific investment $\operatorname{cost}\left(\widehat{C}_{\mathrm{inv}}\right)$ for the different Kalina cycle cases is between $5322.7 \$ \mathrm{~kW}^{-1}$ and $5559.8 \$ \mathrm{~kW}^{-1}$. The values of the key parameters from the thermoeconomic optimization are shown in the Appendix (Table A.1). For a similar capacity plant, the state-of-the-art steam Rankine cycle had an LCOE of 181.0 $\$ \mathrm{MWh}^{-1}$ with the plant specific investment cost $\left(\widehat{C}_{\text {inv }}\right)$ equal to $4822.3 \$ \mathrm{~kW}^{-1}$.

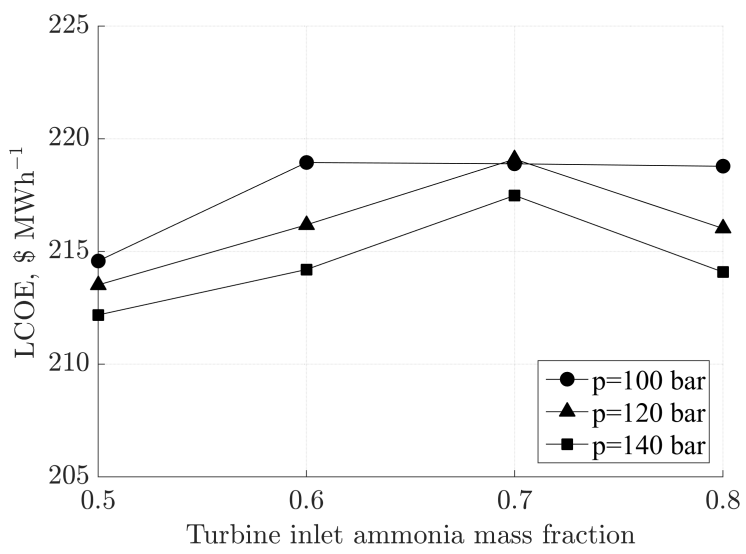

Figure 5: LCOE for the Kalina cycle central receiver CSP plant.

Among the various specific investment costs, the solar field specific investment cost $\left(\widehat{C}_{\mathrm{SF}}\right)$ is directly related to the power cycle efficiency. A cycle with a lower efficiency requires a 
higher heat input for the same net electrical power output. This required heat input then governs the solar field design, and as a result the capital investment cost. This trend may be observed by comparing the respective power cycle efficiency $\left(\eta_{\mathrm{cy}}\right)$ and the solar field specific investment cost $\left(\widehat{C}_{\mathrm{SF}}\right)$ values, and is shown in Fig. 6 for all the simulated combinations of turbine inlet pressures and ammonia mass fractions.

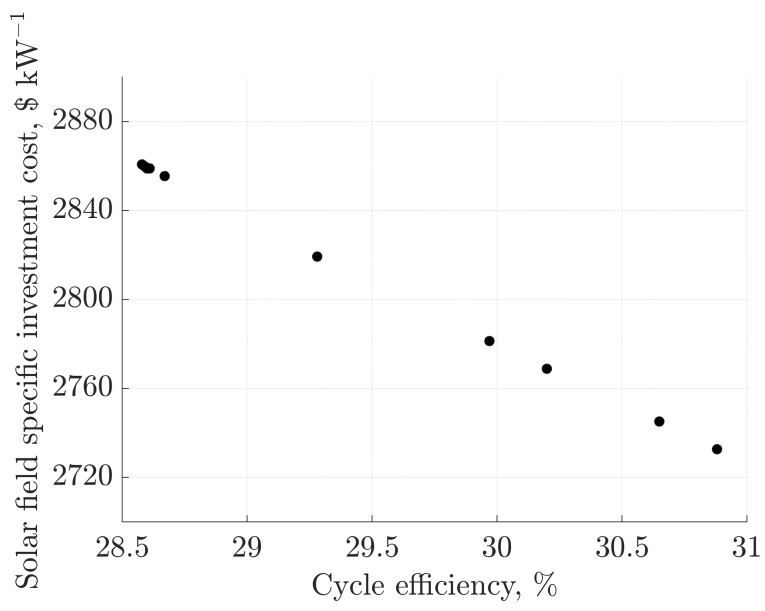

Figure 6: Specific capital investment cost for the solar field $\left(\widehat{C}_{\mathrm{SF}}\right)$ related to the optimal cycle efficiency $\left(\eta_{\text {cy }}\right)$ for the Kalina cycle central receiver CSP plant.

Fig. 7 shows an exemplary breakdown of the total capital investment cost $\left(C_{\text {inv }}\right)$ for a turbine inlet pressure and ammonia mass fraction of 100 bar and 0.5. The other combinations of the turbine inlet pressures and ammonia mass fractions exhibit a similar trend. The various shares in the breakdown of the capital investment costs (the solar field, the power cycle, the land, and the contingency in Fig. 7) exhibit a similar trend as could be found in the open literature $[35,67]$. Fig. 8 shows the breakdown of the capital investment cost for the power cycle equipment $\left(C_{\mathrm{PC} \text {,eqp }}\right)$ for the same case as in Fig. 7 . The turbine and the generator occupy the largest share of the power cycle equipment investment cost, followed by the recuperators, the condensers, the pumps, and lastly the separator. The relatively larger share of the recuperator RE1 among the heat exchangers is because of the pressure and temperature factors used to scale the heat exchanger investment cost. The recuperator RE1 operates with a high pressure on the tube side and relatively higher temperatures than 
the other three heat exchangers (recuperator RE2, and condensers CD1 and CD2).

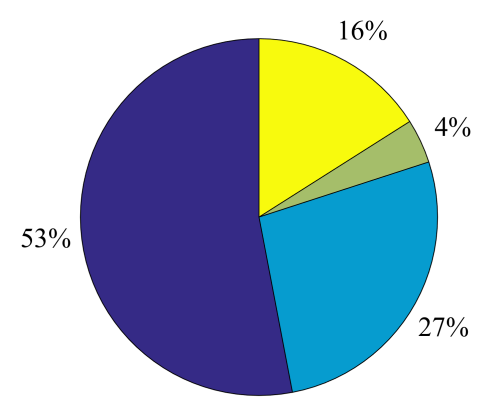

SF $\square$ PC $\square$ LAND $\square$ CNT

Figure 7: Capital cost breakdown for the Kalina cycle CSP plant. 'SF' represents the solar field capital investment cost $\left(C_{\mathrm{SF}}\right)$, 'PC' represents the power cycle capital investment cost $\left(C_{\mathrm{PC}}\right)$, 'LAND' represents the land purchase cost $\left(C_{\text {land }}\right)$, and 'CNT' represents the contingencies $\left(C_{\mathrm{cnt}}\right)$.

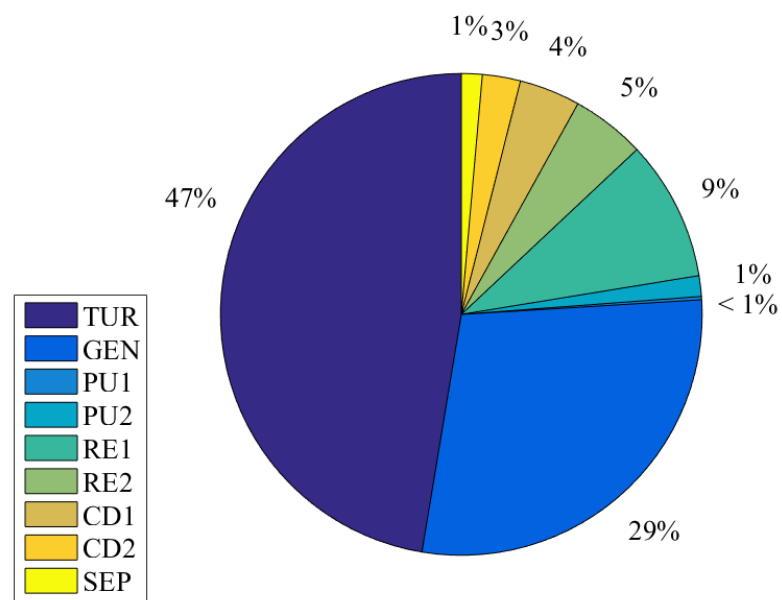

Figure 8: Capital investment cost for the power cycle equipment for the Kalina cycle CSP plant.

Table 2 shows the share of the various costs in the final LCOE for the Kalina cycle with a turbine inlet pressure and ammonia mass fraction of 100 bar and 0.5. The solar field capital investment cost has clearly the highest share in the LCOE, followed by the power cycle total investment cost (equipment plus the miscellaneous expenses). 
Table 2: LCOE breakdown for the Kalina cycle CSP plant for a turbine inlet temperature, pressure, and ammonia mass fraction of $500{ }^{\circ} \mathrm{C}, 100$ bar, and 0.5 .

\begin{tabular}{lll}
\hline LCOE component & Value $\left(\$ \mathrm{MWh}^{-1}\right)$ & Share in LCOE $(\%)$ \\
\hline Solar field capital cost & 101.5 & 47.3 \\
Power cycle equipment capital cost & 22.2 & 10.4 \\
Power cycle miscellaneous expenses & 29.2 & 13.6 \\
Land purchasing cost & 7.6 & 3.5 \\
Contingency & 32.1 & 14.9 \\
Fixed O\&M cost & 18.0 & 8.4 \\
Variable O\&M cost & 4.0 & 1.9 \\
Total & 214.6 & 100 \\
\hline
\end{tabular}

Fig. 9 shows the variation in the LCOE for the Kalina cycle CSP plant with the variation in the solar field capital investment cost $\left(C_{\mathrm{SF}}\right)$, the power cycle capital investment cost $\left(C_{\mathrm{PC}}\right)$, the land purchase cost $\left(C_{\text {land }}\right)$, the contingency $\left(C_{\mathrm{cnt}}\right)$, and the fixed and variable O\&M costs ( $C_{\mathrm{O} \& \mathrm{M}, \mathrm{fix}}$ and $\left.C_{\mathrm{O} \& \mathrm{M}, \mathrm{var}}\right)$. The 'Relative change' on the horizontal axis in the figure is the ratio of the changed parameter value to its optimal value. It may be observed that the LCOE is the most sensitive to the solar field investment cost $\left(C_{\mathrm{SF}}\right)$ which might be expected as the solar field occupies the largest share in the total plant investment cost (Fig. 7). The components such as the separator and the pumps had almost no impact on the LCOE because of their small share in the total plant capital investment cost, and therefore these components were omitted from the sensitivity analysis. A $30 \%$ change in the solar field investment cost $\left(C_{\mathrm{SF}}\right)$ results in about $17 \%$ change in the LCOE. Similarly, a $30 \%$ change in the power cycle investment cost $\left(C_{\mathrm{PC}}\right)$ results in about $9 \%$ change in the LCOE. This is relevant for the Kalina cycle studies with an inherently complex layout resulting in higher capital investment costs. 


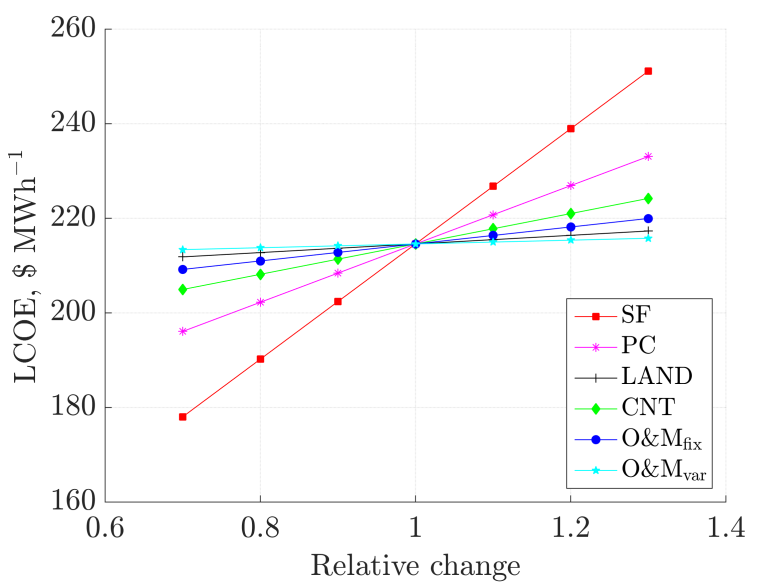

Figure 9: Sensitivity analysis for the different cost parameters for the central receiver CSP plant. 'SF' represents the solar field capital investment cost $\left(C_{\mathrm{SF}}\right)$, 'PC' represents the power cycle capital investment cost $\left(C_{\mathrm{PC}}\right)$, 'LAND' represents the land purchase cost $\left(C_{\text {land }}\right)$, 'CNT' represents the contingencies $\left(C_{\mathrm{cnt}}\right)$, and 'O $\& \mathrm{M}_{\mathrm{fix}}$ ' and 'O\& $\mathrm{M}_{\mathrm{var}}$ ' respectively represent the fixed and variable O\&M costs $\left(C_{\mathrm{O} \& \mathrm{M}, \mathrm{fix}}\right.$ and $\left.C_{\mathrm{O} \& \mathrm{M}, \mathrm{var}}\right)$.

Figs. 10 and 11 respectively show the effect of the individual elements of the solar field and the power cycle cost parameters on the LCOE. From the solar field, the tower has the least effect on the LCOE, whereas the heliostat mirrors have the highest effect. A $30 \%$ change in the heliostat mirror (collector) capital investment cost $\left(C_{\text {col }}\right)$ results in about $10 \%$ change in the LCOE, which is slightly more than the variation for the entire power cycle capital investment cost $\left(C_{\mathrm{PC}}\right)$. Among the power cycle equipment, the turbine cost $\left(C_{\text {tur }}\right)$ has the highest impact on the LCOE, followed by the generator, and lastly the heat exchangers. A $30 \%$ change in the turbine capital investment cost $\left(C_{\text {tur }}\right)$ results in about $4 \%$ change in the LCOE. 


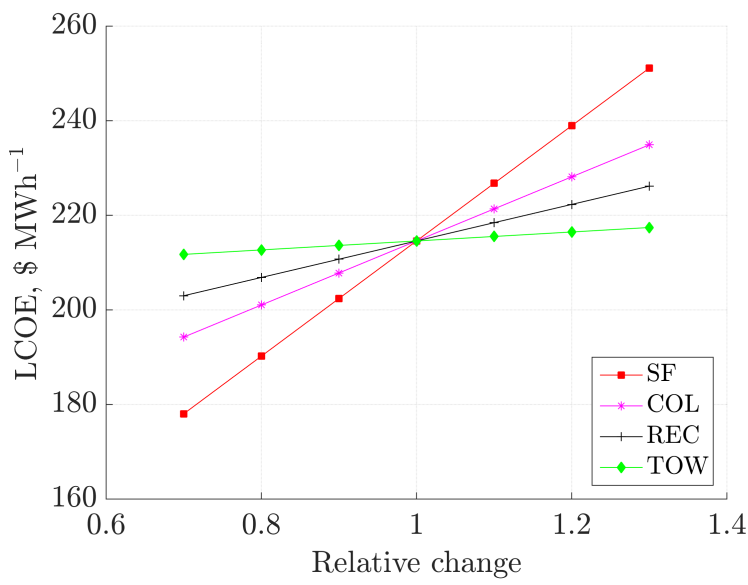

Figure 10: Sensitivity analysis for the different solar field cost parameters for the central receiver CSP plant. 'SF' represents the solar field capital investment cost $\left(C_{\mathrm{SF}}\right)$, 'COL' represents the heliostat mirror collector capital investment cost $\left(C_{\mathrm{col}}\right)$, 'REC' represents the solar receiver capital investment cost $\left(C_{\text {rec }}\right)$, and 'TOW' represents the tower capital investment cost $\left(C_{\text {tow }}\right)$.

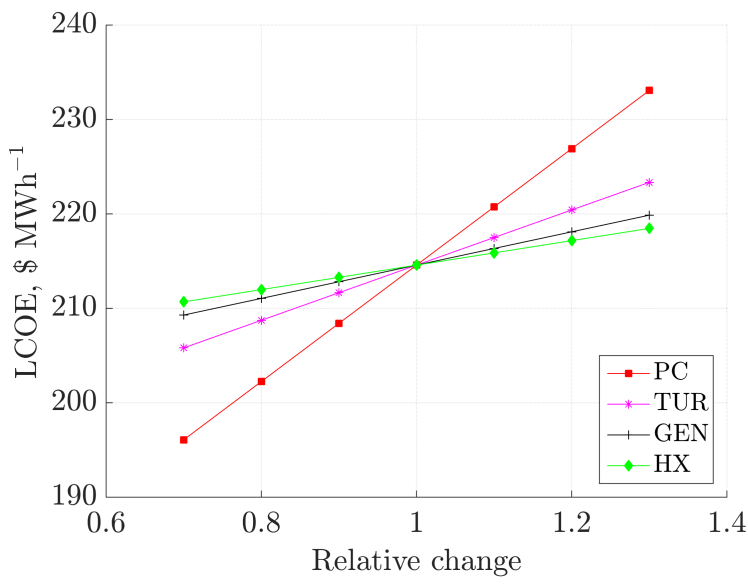

Figure 11: Sensitivity analysis for the different power cycle cost parameters for the central receiver CSP plant. 'PC' represents the power cycle capital investment cost $\left(C_{\mathrm{PC}}\right)$, 'TUR' represents the turbine capital investment cost $\left(C_{\text {tur }}\right)$, 'GEN' represents the generator capital investment cost $\left(C_{\text {gen }}\right)$, and 'HX' represents the total heat exchanger capital investment $\operatorname{cost}\left(\sum C_{\mathrm{re}}+\sum C_{\mathrm{cd}}\right)$.

\section{Discussion}

The Kalina cycle has a higher specific capital investment cost $\left(\widehat{C}_{\text {inv }}\right)$ and a higher LCOE than the steam Rankine cycle. This is mainly because of two reasons: (1) worse power 
cycle efficiency than the corresponding steam Rankine cycle configuration resulting in a larger solar field requirement for the same net electrical power output, and (2) the higher capital investment cost for the power cycle itself. These reasons highlight the importance of comparing the different power cycles also based on economics and not solely on thermodynamic indicators, since the thermodynamic comparison does not ensure equal costs for the compared power cycles, but rather a favouring of the Kalina cycle. Although the specific investment costs for the Kalina cycle are still within the ranges for the contemporary CSP plants without storage, between $4500 \$ \mathrm{~kW}^{-1}$ and $7150 \$ \mathrm{~kW}^{-1}$ [68], the costs are still on the higher side. The contemporary LCOE values for various CSP plants are between $146 \$ \mathrm{MWh}^{-1}$ and $213 \$ \mathrm{MWh}^{-1}$ [69], whereas for the Kalina cycles, the LCOE was found to be between about $212 \$ \mathrm{MWh}^{-1}$ and $219 \$ \mathrm{MWh}^{-1}$, generally outside the range of the contemporary values. A similar trend was observed in a recent study by Ashouri et al. [16] where the LCOE for the CSP plant with Kalina cycle was found to be significantly higher than a fossil fuel fired Kalina cycle, albeit for a low temperature application (with a turbine inlet temperature of $106^{\circ} \mathrm{C}$ ).

Kalina et al. [70] also presented a cost analysis based on the purchased equipment cost for both the Kalina and the steam Rankine cycles. The Kalina cycle layout KCS6 was used for comparison. The purchasing cost of the Kalina cycle (1058 $\$ \mathrm{~kW}^{-1}$ in 1991 values) as a gas turbine bottoming cycle was found to be slightly higher than that of the steam Rankine cycle (1033 $\$ \mathrm{~kW}^{-1}$ in 1991 values). In the current study, it might be argued that the steam Rankine cycle's specific capital investment cost for the state-of-the-art configuration with reheat and several feedwater heaters could be higher than the default value suggested by NREL [42]. However, even when the steam Rankine cycle specific capital investment cost is increased to 1.5 times the default value, the obtained LCOE is $207.0 \$ \mathrm{MWh}^{-1}$. This value is still lower than the lowest achievable LCOE for the Kalina cycle cases, mainly because of the larger required solar field and its associated cost. As may be observed from the sensitivity analysis (Fig. 9), the only way for the Kalina cycle to obtain the LCOE equivalent to the steam Rankine cycle is by reducing the solar field cost by at least $30 \%$. This implies that for large scale CSP plants, the key to significantly reducing the CSP plant costs is through 
a cheaper solar field.

On the whole, the use of the Kalina cycle for high temperature CSP applications has its own advantages and disadvantages. The advantages include the possibility of all the cycle components operating at above atmospheric pressure, to be able to improve the part-load

\section{Conclusion}

The methodology and the results from the thermoeconomic optimization of the Kalina cycle layout KC12 for a central receiver CSP plant are presented and discussed. The Kalina cycle has an added degree of freedom in terms of the ammonia mass fraction, as compared with using a pure fluid, which can be varied for a better part-load performance. However, the achievable design point cycle efficiencies are lower than the state-of-the-art steam Rankine cycles for high temperature applications. This results in requiring larger solar fields for the same rated plant capacity, thereby significantly increasing the capital investment cost. This causes the LCOE for nearly all the considered Kalina cycle cases to be outside the range of the LCOE values for the contemporary CSP plants. Thus the results from this study suggest that it is not beneficial to use the Kalina cycle for high temperature CSP applications.

\section{Acknowledgements}

The authors thank Brian Ehrhart, University of Colorado at Boulder, USA for his guidance on the use of the DELSOL3 software and for the general discussions on central receiver 
CSP plants; Eric Lemmon, National Institute of Standards and Technology, USA for providing the 'Ammonia (Lemmon)' fluid property formulation for REFPROP; S.M.I. Karimulla, Arani Power Systems Ltd, India for the information on the Kalina cycle turbines; and Bengt Perers, Technical University of Denmark, Denmark for the useful discussion and for providing the solar radiation data used in the annual performance analysis.

\section{Nomenclature}

\begin{tabular}{|c|c|}
\hline$A$ & area, $\mathrm{m}^{2}$ \\
\hline${ }^{160} \quad \alpha_{r e c}$ & receiver absorptivity \\
\hline$C$ & cost, $\$$ \\
\hline$\widehat{C}$ & specific cost, $\$ \mathrm{~kW}^{-1}$ \\
\hline $\mathrm{CRF}$ & capital recovery factor \\
\hline CSP & concentrating solar power \\
\hline${ }_{65} D$ & diameter, m \\
\hline DNI & direct normal irradiance, $\mathrm{W} \mathrm{m}^{-2}$ \\
\hline$E$ & electricity, MWh \\
\hline$\eta$ & efficiency \\
\hline$f$ & factor, defined locally where used \\
\hline $70 \quad F_{c u}$ & copper loss fraction \\
\hline GA & Genetic algorithm \\
\hline$H$ & height, m \\
\hline$k_{d}$ & real debt interest rate \\
\hline$k_{i}$ & insurance rate \\
\hline$k_{t u r}$ & turbine constant, $\operatorname{kg~K} \mathrm{K}^{0.5} \mathrm{~s}^{-1}$ bar $^{-1}$ \\
\hline
\end{tabular}

LCOE levelized cost of electricity, $\$ \mathrm{MWh}^{-1}$

$\dot{m} \quad$ mass flow rate, $\mathrm{kg} \mathrm{s}^{-1}$

$N \quad$ rotation speed, $\mathrm{rpm}$

${ }_{480} \quad N_{p} \quad$ plant lifetime in years

O\&M operations and maintenance

$p \quad$ pressure, bar

$\pi \quad$ universal constant, 3.1416

$\dot{Q} \quad$ rate of heat transfer, MW

${ }_{485} \rho_{c o l}$ heliostat mirror (collector) reflectivity

$T$ temperature, ${ }^{\circ} \mathrm{C}$

$\bar{T} \quad$ average temperature, ${ }^{\circ} \mathrm{C}$

$U$ overall heat transfer coefficient, $\mathrm{W} \mathrm{m} \mathrm{m}^{-2} \mathrm{~K}^{-1}$

$\dot{W} \quad$ mechanical or electrical power, MW

$X \quad$ vapour quality, $\mathrm{kg} \mathrm{kg}^{-1}$

$x \quad$ ammonia mass fraction, $\mathrm{kg} \mathrm{s}^{-1}$ 
$\zeta \quad$ relative load

495

Subscripts and components

abs absorbed energy by receiver working fluid

atm atmospheric transmittance

blo blocking

500 cd condenser

CF cost function

cln mirror cleanliness

cnt contingency

col heliostat mirror collector

$505 \cos$ cosine effect

cw condenser cooling water

d design

el electrical equipment and material

eqp power cycle equipment

${ }_{510}$ fix fixed

gen generator

hx heat exchanger

inc energy available on the receiver surface before receiver thermal loss

insc instrumentation and control

inst installation

inv investment is isentropic

land required land area

520 loss loss

m mechanical

M\&S Marshall and Swift equipment cost index

min minimum

525 misc power cycle miscellaneous cost

mx mixer

net net electrical power output

PC power cycle

pip piping

${ }_{530} \quad$ pp pinch point

pres pressure

pu pump

re recuperator

rec solar central receiver

535 sep separator

SF solar field

sha shadowing

site plant site improvement

sol available solar energy

$540 \quad$ spg spillage

spl splitter

temp temperature 


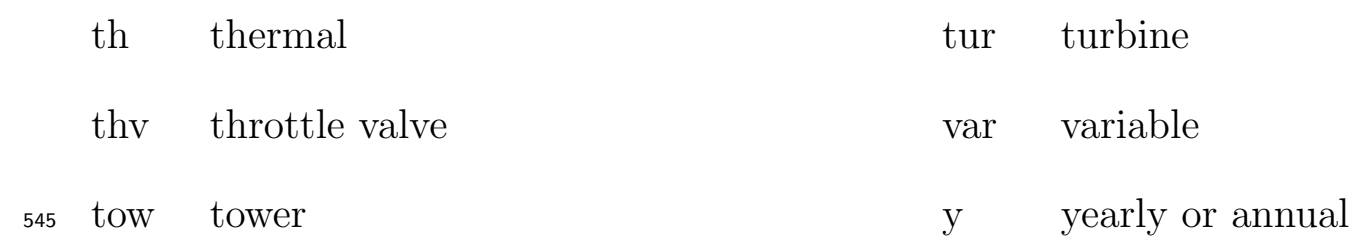

\section{Appendix}

550 Fig. A.1 shows the cycle nominal operating state for an exemplary thermoeconomically optimal solution for a turbine inlet temperature, pressure, and ammonia mass fraction of $500{ }^{\circ} \mathrm{C}, 100$ bar, and 0.5. The main results from the thermoeconomic optimization of the Kalina cycle central receiver CSP plant for all the simulated combinations of the turbine inlet pressures and ammonia mass fractions at a turbine inlet temperature of $500{ }^{\circ} \mathrm{C}$ are 555 shown in Table A.1. 


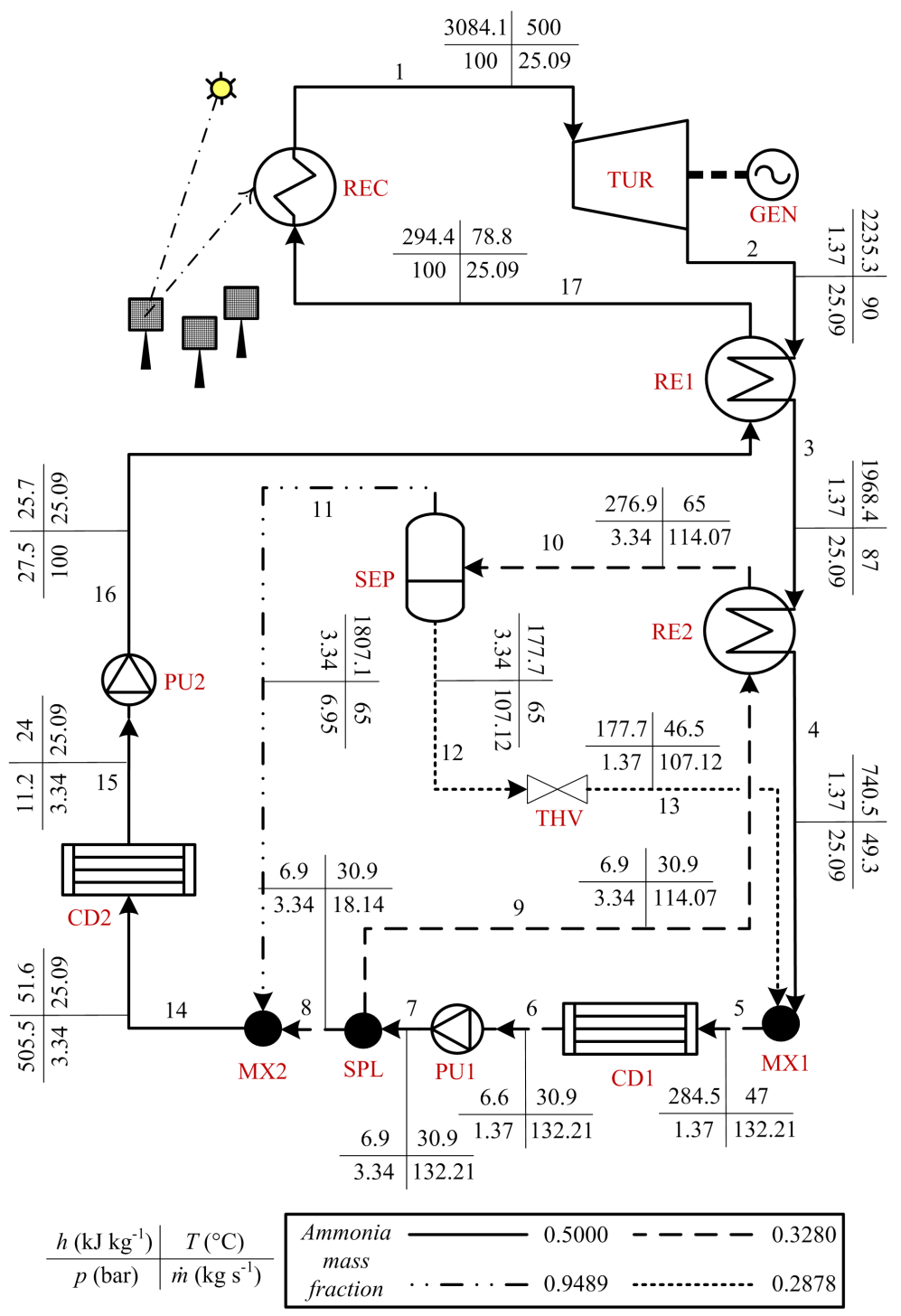

Figure A.1: Cycle nominal operating state for the thermoeconomic optimum for a turbine inlet temperature, pressure, and ammonia mass fraction of $500{ }^{\circ} \mathrm{C}, 100 \mathrm{bar}$, and 0.5 . 
Table A.1: Thermoeconomic optimization results for the Kalina cycle central receiver CSP plant at a turbine inlet temperature of $500{ }^{\circ} \mathrm{C}$.

\begin{tabular}{ccccccccc}
\hline$x_{1}$ & $p_{1}$ & $\eta_{\text {cy }}$ & $\widehat{C}_{\text {inv }}$ & $\widehat{C}_{\mathrm{SF}}$ & $\widehat{C}_{\mathrm{PC}}$ & $\widehat{C}_{\text {land }}$ & $\widehat{C}_{\mathrm{cnt}}$ & $\mathrm{LCOE}$ \\
& $(\mathrm{bar})$ & $(\%)$ & $\left(\$ \mathrm{~kW}^{-1}\right)$ & $\left(\$ \mathrm{~kW}^{-1}\right)$ & $\left(\$ \mathrm{~kW}^{-1}\right)$ & $\left(\$ \mathrm{~kW}^{-1}\right)$ & $\left(\$ \mathrm{~kW}^{-1}\right)$ & $\left(\$ \mathrm{MWh}^{-1}\right)$ \\
\hline 0.5 & 100 & 28.58 & 5427.3 & 2860.8 & 1447.9 & 214.1 & 904.6 & 214.6 \\
& 120 & 28.67 & 5380.3 & 2855.5 & 1414.6 & 213.9 & 896.7 & 213.5 \\
& 140 & 28.58 & 5359.8 & 2860.8 & 1391.7 & 214.1 & 893.3 & 212.2 \\
0.6 & 100 & 28.61 & 5559.8 & 2859.0 & 1560.3 & 213.9 & 926.6 & 218.9 \\
& 120 & 28.60 & 5482.2 & 2859.0 & 1495.6 & 213.9 & 913.7 & 216.2 \\
& 140 & 28.59 & 5428.7 & 2859.9 & 1450.1 & 214.0 & 904.8 & 214.2 \\
0.7 & 100 & 28.58 & 5530.0 & 2860.8 & 1533.5 & 214.1 & 921.7 & 218.9 \\
& 120 & 29.28 & 5463.8 & 2819.3 & 1524.1 & 209.8 & 910.6 & 219.1 \\
& 140 & 30.20 & 5445.3 & 2768.9 & 1564.1 & 204.7 & 907.5 & 217.5 \\
0.8 & 100 & 29.97 & 5432.3 & 2781.3 & 1539.7 & 206.0 & 905.4 & 218.8 \\
& 120 & 30.65 & 5372.6 & 2745.1 & 1529.7 & 202.4 & 895.4 & 216.0 \\
\hline & 140 & 30.88 & 5322.7 & 2732.7 & 1501.7 & 201.2 & 887.1 & 214.1 \\
\hline
\end{tabular}

\section{References}

[1] Greenpeace International, SolarPACES, and ESTELA. Concentrating Solar Power: Global Outlook 2009. Technical report, Amsterdam, Netherlands, 2009.

[2] A.I. Kalina. Combined-cycle system with novel bottoming cycle. Journal of Engineering for Gas Turbines and Power, 106:737-742, 1984.

[3] M.R. Kærn, A. Modi, J.K. Jensen, and F. Haglind. An assessment of transport property estimation methods for ammonia-water mixtures and their influence on heat exchanger size. International Journal of Thermophysics, 36(7):1468-1497, 2015.

[4] A. Coskun, A. Bolatturk, and M. Kanoglu. Thermodynamic and economic analysis and optimization of power cycles for a medium temperature geothermal resource. Energy Conversion and Management, $78: 39-49,2014$. 
[5] P. Bombarda, C.M. Invernizzi, and C. Pietra. Heat recovery from diesel engines: A thermodynamic comparison between Kalina and ORC cycles. Applied Thermal Engineering, 30(2-3):212-219, 2010.

[6] H. Junye, C. Yaping, and W. Jiafeng. Thermal performance of a modified ammonia-water power cycle for reclaiming mid/low-grade waste heat. Energy Conversion and Management, 85:453-459, 2014.

[7] C. Yue, D. Han, W. Pu, and W. He. Comparative analysis of a bottoming transcritical ORC and a Kalina cycle for engine exhaust heat recovery. Energy Conversion and Management, 89:764-774, 2015.

[8] P. Zhao, J. Wang, and Y. Dai. Thermodynamic analysis of an integrated energy system based on compressed air energy storage (CAES) system and Kalina cycle. Energy Conversion and Management, 98:161-172, 2015.

[9] V. Zare, S.M.S. Mahmoudi, and M. Yari. On the exergoeconomic assessment of employing Kalina cycle for GT-MHR waste heat utilization. Energy Conversion and Management, 90:364-374, 2015.

[10] S. Ogriseck. Integration of Kalina cycle in a combined heat and power plant, a case study. Applied Thermal Engineering, 29(14-15):2843-2848, 2009.

[11] Z. Zhang, Z. Guo, Y. Chen, J. Wu, and J. Hua. Power generation and heating performances of integrated system of ammonia-water Kalina-Rankine cycle. Energy Conversion and Management, 92:517-522, 2015.

[12] O.K. Singh and S.C. Kaushik. Energy and exergy analysis and optimization of Kalina cycle coupled with a coal fired steam power plant. Applied Thermal Engineering, 51(1-2):787-800, 2013.

[13] O.K. Singh and S.C. Kaushik. Thermoeconomic evaluation and optimization of a Brayton-RankineKalina combined triple power cycle. Energy Conversion and Management, 71:32-42, 2013.

[14] J. Wang, Z. Yan, E. Zhou, and Y. Dai. Parametric analysis and optimization of a Kalina cycle driven by solar energy. Applied Thermal Engineering, 50(1):408-415, 2013.

[15] F. Sun, W. Zhou, Y. Ikegami, K. Nakagami, and X. Su. Energy-exergy analysis and optimization of the solar-boosted Kalina cycle system 11 (KCS-11). Renewable Energy, 66:268-279, 2014.

[16] M. Ashouri, A.M. Khoshkar Vandani, M. Mehrpooya, M.H. Ahmadi, and A. Abdollahpour. Technoeconomic assessment of a Kalina cycle driven by a parabolic Trough solar collector. Energy Conversion and Management, 105:1328-1339, 2015.

[17] C.H. Marston. Parametric analysis of the Kalina cycle. Journal of Engineering for Gas Turbines and Power, 112:107-116, 1990.

[18] C.H. Marston and M. Hyre. Gas turbine bottoming cycles: Triple-pressure steam versus Kalina. Journal of Engineering for Gas Turbines and Power, 117(January):10-15, 1995.

[19] M.B. Ibrahim and R.M. Kovach. A Kalina cycle application for power generation. Energy, 18(9):961969, 1993.

[20] P.K. Nag and A.V.S.S.K.S. Gupta. Exergy analysis of the Kalina cycle. Applied Thermal Engineering, 
18(6):427-439, 1998.

[21] E. Thorin. Power cycles with ammonia-water mixtures as working fluid. Phd thesis, KTH Royal Institute of Technology, Stockholm, Sweden, 2000.

[22] C. Dejfors, E. Thorin, and G. Svedberg. Ammonia-water power cycles for direct-fired cogeneration applications. Energy Conversion and Management, 39(16-18):1675-1681, 1998.

[23] A. Modi, T. Knudsen, F. Haglind, and L.R. Clausen. Feasibility of using ammonia-water mixture in high temperature concentrated solar power plants with direct vapour generation. Energy Procedia, 57:391-400, 2014.

[24] A. Modi and F. Haglind. Performance analysis of a Kalina cycle for a central receiver solar thermal power plant with direct steam generation. Applied Thermal Engineering, 65(1-2):201-208, 2014.

[25] A. Modi and F. Haglind. Thermodynamic optimisation and analysis of four Kalina cycle layouts for high temperature applications. Applied Thermal Engineering, 76:196-205, 2015.

[26] A. Modi, J.G. Andreasen, M.R. Kærn, and F. Haglind. Part-load performance of a high temperature Kalina cycle. Energy Conversion and Management, 105:453-461, 2015.

[27] X. Zhang, M. He, and Y. Zhang. A review of research on the Kalina cycle. Renewable and Sustainable Energy Reviews, 16(7):5309-5318, 2012.

[28] M.D. Mirolli. Kalina cycle power systems in waste heat recovery applications. Www.globalcement.com/magazine/articles/ 721-kalina-cycle-power-systems-in-waste-heat-recovery-applications. Accessed: 2015-0708 .

[29] A.I. Kalina. Method of preventing nitridation or carburization of metals. United States Patent 6482272 B2, 2002.

[30] Kalex LLC. Kalina cycle power systems for solar-thermal applications. www.kalexsystems.com/ KalexSolarThermalBrochure7-11.pdf. Accessed: 2015-06-13.

[31] H. Chen, D.Y. Goswami, M.M. Rahman, and E.K. Stefanakos. A supercritical Rankine cycle using zeotropic mixture working fluids for the conversion of low-grade heat into power. Energy, 36(1):549-555, 2011.

[32] Meteotest. Meteonorm. www.meteonorm.com. Accessed: 2015-09-10.

[33] C.-J. Winter, R.L. Sizmann, and L.L. Vant-Hull, editors. Solar power plants. Springer-Verlag, Heidelberg, Germany, 1st edition, 1991.

[34] K. Lovegrove and W. Stein, editors. Concentrating solar power technology: Principles, Developments and Applications. Woodhead Publishing Limited, Cambridge, UK, 1st edition, 2012.

[35] R. Pitz-Paal, J. Dersch, and B. Milow. ECOSTAR European Concentrated Solar Thermal RoadMapping. Technical report, DLR, 2005. 
[36] MathWorks. MATLAB. www.mathworks.se/products/matlab. Accessed: 2015-03-16.

[37] Sandia National Laboratories. DELSOL. http://energy.sandia.gov/energy/renewable-energy/ solar-energy/csp-2/csp-codes-and-tools/. Accessed: 2015-06-24.

[38] National Institute for Standards and Technology. REFPROP MATLAB Interface. www . boulder.nist. gov/div838/theory/refprop/LINKING/Linking.htm\#MatLabApplications. Accessed: 2015-04-08.

[39] R. Tillner-Roth and D.G. Friend. A Helmholtz free energy formulation of the thermodynamic properties of the mixture \{water+ammonia\}. Journal of Physical and Chemical Reference Data, 27(1):63-96, 1998.

[40] E. Lemmon. National Institute of Standards and Technology. Private communication, 2013.

[41] A. Modi. Numerical evaluation of the Kalina cycle for concentrating solar power plants. Phd thesis, Technical University of Denmark, Kongens Lngyby, Denmark, 2015.

[42] NREL. System Advisor Model. www.sam.nrel.gov. Accessed: 2015-06-25.

[43] M.R. Kærn, A. Modi, J.K. Jensen, J.G. Andreasen, and F. Haglind. An assessment of in-tube flow boiling correlations for ammonia-water mixtures and their influence on heat exchanger size. Applied Thermal Engineering, 93:623-638, 2016.

[44] P.K. Nag. Power plant engineering. Tata Mc-Graw Hill Publishing Company Limited, New Delhi, India, 3rd edition, 2008.

[45] R. Smith. Chemical Process - Design and Integration. John Wiley \& Sons, Ltd., West Sussex, 2005.

[46] R.K. Sinnott. Coulson \& Richardson's Chemical Engineering Volume 6. Elsevier ButterworthHeinemann, Oxford, UK, 4th edition, 2005.

[47] T.L. Bergman, A.S. Lavine, F.P. Incropera, and D.P. Dewitt. Fundamentals of heat and mass transfer. John Wiley \& Sons, Inc., Jefferson City, USA, 7th edition, 2011.

[48] M.M. Shah, A.M. Mahmoud, and J. Lee. An assessment of some predictive methods for in-tube condensation heat transfer of refrigerant mixtures. ASHRAE Transactions, 119(2):38-51, 2013.

[49] K.J. Bell and M.A. Ghaly. An approximate generalized design method for multicomponent/partial condensers. In 13th National Heat Transfer Conference, Denver, Colorado, USA, 1972. AIChE-ASME.

[50] M.M. Shah. Chart correlation for saturated boiling heat transfer: equations and further study. ASHRAE Transactions, 88(1):185-196, 1982.

[51] D.Q. Kern. Process Heat Transfer. McGraw-Hill Book Company, Singapore, 1950.

[52] D.H. Cooke. Modeling of off-design multistage turbine pressures by Stodola's ellipse. In Energy Incorporated PEPSE User's Group Meeting, pages 205-234, Richmond, Virginia, USA, 1983. Bechtel Power Corporation.

[53] A. Ray. Dynamic modelling of power plant turbines for controller design. Applied Mathematical Modelling, 4(2):109-112, 1980.

[54] F. Lippke. Simulation of the part-load behavior of a 30 MWe SEGS plant. Technical report, Sandia 
National Laboratories, SAND95-1293, 1995.

68] IRENA. Renewable energy Technologies: Cost Analysis Series - Concentrating solar power. Technical report, International Renewable Energy Agency, 2012.

[69] OECD and IEA. Technology roadmap - Solar thermal electricity. Technical report, International Energy Agency, Paris Cedex, France, 2014.

[70] A.I. Kalina, H.M. Leibowitz, D.W. Markus, and R.I. Pelletier. Further technical aspects and economics of a utility-size Kalina bottoming cycle. In Gas Turbine and Aeroengine Congress and Exposition, Orlando, Florida, USA, 1991. ASME. 
[71] C.H. Marston. Development of the adjustable proportion fluid mixture cycle. Mechanical Engineering, 114(9):76-81, 1992. 